\begin{abstract}
Among the Dark Triad traits (psychopathy, narcissism, and Machiavellianism) Machiavellianism is uniquely associated with flexibility. This flexibility should result in the use of aggressive short-term tactics only when they do not interfere with long-term goals. Study 1 found that individuals high in Machiavellianism differed from those high in psychopathy with respect to retrospective accounts of negative mate retention tactics. Study 2 found an interaction between Machiavellianism and relationship type such that individuals high in Machiavellianism tempered the use of negative tactics for long-term (but not short-term) relationships. The findings highlight the flexibility of the Machiavellianism construct and its relevance for mating strategies among the Dark Triad.
\end{abstract}

Keywords: Dark Triad; psychopathy; narcissism; Machiavellianism; Mate Retention; Mating Strategies 


\section{Machiavellian flexibility in negative mate retention}

The Dark Triad consists of three overlapping but empirically and conceptually distinguishable personality constructs (Paulhus \& Williams, 2002). These traits are: impulsive and aggressive psychopathy (e.g., Cleckley, 1976), calculating and manipulative Machiavellianism (Christie \& Geis, 1970), and self-aggrandizing and grandiose narcissism (Kernberg, 1975; Kohut, 1971). Note that psychopathy and narcissism in this paper will refer to subclinical forms (i.e., those found in non-institutionalized populations; LeBreton, Binning, \& Adorno, 2005). Further, Machiavellianism is conceptualized as a personality trait in the normal range, and as such it is not considered a disorder (Christie \& Geis, 1970). These traits typically correlate with each other between .30-.50 (O’Boyle, Forsyth, Banks, \& McDaniel, 2012). The Dark Triad constructs share the same location in interpersonal space, which is high dominance and low nurturance (Jones \& Paulhus, 2011a) and in general, all three traits are callous and manipulative (Jones \& Figueredo, 2013).

However, Machiavellianism is unique among the Dark Triad traits in two key ways. First, individuals high in Machiavellianism are cynical (Christie \& Geis, 1970), which leads them to assume that most (if not all) people are only out for themselves. Second, individuals high in Machiavellianism are flexible in their manipulation tactics and interpersonal interactions (Bereczkei, 2015). They monitor and anticipate the moves of others in competitive games (Esperger \& Bereczkei, 2012), and try to stay one step ahead of others (Czibor \& Bereczkei, 2012). Further, they remain flexible in their strategies towards accomplishing their final goals. Bereczkei and colleagues (2013) found that individuals high in Machiavellianism have neurological structures that suggest caution when engaging in social interactions. Such 
individuals also have structural differences in the brain suggesting Machiavellianism is associated with increased reward sensitivity and delay of gratification (Bagozzi et al., 2013; Spitzer et al., 2007; Verbeke et al., 2011). Thus, individuals high in Machiavellianism have the neurological signature of a strategic manipulator.

These strategic qualities should be present in romantic relationships as well. In order to maximize their goals (whatever those may be), individuals high in Machiavellianism are likely to behave in ways that are tailored to their current situation. For example, Buss (1988) argued that harsh and aggressive behaviors can be used to deter infidelity at the cost of relationship longevity. Thus, in short-term relationships, which we define here as those relationships that lack commitment or a desire for the relationship to last, individuals high in Machiavellianism would use aggressive behaviors to ward off infidelity or gain a reproductive advantage. In contrast, in long-term relationships, which we define here as those relationships involving commitment and a desire for the relationship to last, individuals high in Machiavellianism would forgo such behaviors because of the potential repercussions they may have for the individual's long-term goals. In sum, given that individuals high in Machiavellianism have a "whatever is necessary" mentality towards their goals, they are likely to be willing to treat romantic partners aggressively, if it would be beneficial to do so in a given situation. However, if such behaviors would be antithetical to their goals in a different situation, they would likely curtail the use of such behaviors. Thus, individuals high in Machiavellianism would only object to aggressive mate treatment based on strategic reasons, not ethical ones (Jones, 2016).

A partner's willingness to treat others in a callous fashion plays a central role in interpersonal relationships (Kenrick \& Trost, 1989). In particular, callousness facilitates exploitative mating strategies (Harms, Williams, \& Paulhus, 2001; McHoskey, 2001; Reise \& 
Wright, 1996, Jonason, Li, Webster, \& Schmitt, 2009). Such behavior appears to be successful in achieving increased sexual engagement (Eysenck, 1976, pp. 19-20, 46; Harms et al., 2001; Linton \& Weiner, 2001). One potential reason is that callous behaviors might promote sexual activity through behaviors such as insincere commitment, feigned mate value, and other forms of sexual deception (Seto, Khattar, Lalumiere, \& Quinsey, 1997; Tooke \& Camire, 1991). Another potential explanation is that some potential mates are attracted to those with a dominant and harsh veneer (Hawley, Little, \& Card, 2007). In spite of their overlapping callousness, individuals high in the different Dark Triad traits exhibit distinct interpersonal strategies (Jones \& Paulhus, 2011a). Such differences should carry over to differences in mating strategies. Mating strategies can be conceptualized on a continuum from long- to short-term. Longterm or "slow" reproductive strategies involve caring for offspring, securely attaching to a partner and higher levels of parental investment (e.g., Figueredo, et al., 2005; 2006; 2007). Short-term or "fast" strategies involve seeking novel partners and immediate sexual gratification (e.g., Rowe, Vazsonyi, \& Figueredo, 1997). The pursuit of both strategies, strategic pluralism, involves tactical allocation in the service of both short-term and long-term mating pursuits (Gangestad \& Simpson, 2000). However, individuals deficient in impulse control are unlikely to pursue long-term strategies (Figueredo et al., 2006).

Some researchers have claimed that individuals high in any of the Dark Triad traits are universally short-term (Jonason, Koenig, \& Trost, 2010) or have a fast "Life History Strategy" or LHS (Jonason et al., 2012). However, a lack of behavioral flexibility is part of the definition of a fast LHS (Figueredo et al., 2006). Notwithstanding, Machiavellianism does not fit this rigid pattern of short-term mating focus (Czibor \& Berezckei, 2012). Although correlated with indices of a fast LHS (McDonald, Donnellan, \& Navarette, 2012), Individuals high in 
Machiavellianism have shown substantial flexibility both in social situations (Bereczkei, 2015) and in developmental plasticity (Vernon, Vickers, Villani, \& Harris, 2008). Further, Machiavellianism is negatively associated with short-term sexual behaviors (Jones \& de Roos, in press). Thus, individuals high in Machiavellianism do not seem to be short-term in their mating strategy. Finally, Gladden, Figueredo and Jacobs (2009) indicate that having a short-term mating orientation is not synonymous with having an antisocial disposition.

Of the three Dark Triad traits, psychopathy is most closely aligned with a fast LHS (Mealey, 1995). Evidence for this assertion comes from the fact that psychopathy is defined through deficits in impulse control (Blair, 2001; Newman, 1987), rigid behavioral responding (Newman \& Kosson, 1986), and a short-term focus (Jonason \& Tost, 2010). In contrast, individuals high in Machiavellianism possess strategic cognitive capabilities (Bereckzei, 2015; Hawley, 2003; Jones \& Paulhus, 2009), that are not part of the fast LHS definition. Therefore, we would expect individuals high in Machiavellianism to vary their mating strategies based upon the goals of the situation at hand.

Finally, individuals high in narcissism are more short-term than are individuals high in Machiavellianism. Although individuals high in narcissism have interpersonal problems due to their impulsivity (Vazire \& Funder, 2006), research suggests that these impulsivity problems stem from overconfidence (Campbell, Goodie, \& Foster, 2004) rather than deficits in impulse control (Jones \& Paulhus, 2011b). It should also be noted that narcissistic charm is most effective upon first encounters (Back, Schmukle, \& Egloff, 2010), and wears off over time (Paulhus, 1998). In spite of their associations with impulsivity, individuals high in narcissism have superior impulse control when compared to individuals high in psychopathy (Jones \& Paulhus, 2011b). Nevertheless, both narcissism and psychopathy are linked to short-term mating 
(Reise \& Wright, 1996).

\section{Poor Mate Treatment}

By poor mate treatment, we refer to those behaviors that would harm a relationship or a relationship partner. Research on accommodation processes, which are behaviors designed to curtail relationship-destructive reactions, argues that individuals willing to inhibit destructive impulses have greater commitment and longevity in their relationships (Rusbult, Bissonnette, Arriaga, Cox, \& Bradbury, 1998). Individuals can be destructive in ways that are active (e.g., behaving abusively) or passive (e.g., ignoring one's partner). Individuals high in

Machiavellianism are not reactively aggressive (Jones \& Paulhus, 2010), and have typical levels of impulse control (Jones \& Paulhus, 2011b). Thus, for individuals high in Machiavellianism, poor mate treatment would probably not stem from impulsivity, anger, or ego-threat, but rather instrumental gain (Kerig \& Stellwagon, 2010). In contrast to Machiavellianism, individuals high in psychopathy lack impulse control, and individuals high in narcissism have a fragile sense of self (Morf \& Rhodewalt, 2001), both of which predict reactionary aggression (Jones \& Paulhus, 2010). Because there is no reactionary aggression associated with Machiavellianism, individuals high in Machiavellianism have the cognitive mechanisms necessary to engage in accommodation processes (Bereczkei et al., 2013). However, it is important to note that their willingness to engage in accommodation processes would depend entirely on what they stand to gain instrumentally, by doing so. Thus, individuals high in Machiavellianism are likely to engage in relationship accommodation only in order to maximize their personal outcomes.

In the realm of relationship aspirations, instrumental gain could be defined as retaining a partner, deterring infidelity in a partner, or finding new partners.

Although psychopathy and narcissism are at the short-term end of mating, obtaining 
sexual partners is only one piece of a larger mating puzzle. Even non-monogamous individuals need to ward off rivals and retain partners long enough to ensure fertilization has occurred (Thornhill \& Alcock, 1983). Given that individuals high in psychopathy are exclusively shortterm (Mealey, 1995), using coercion and charm in the service of increasing sexual variety (Seto et al., 1997), they have more children than do individuals low in psychopathy (Harris, Lalumière, \& Rice, 1997). Thus, individuals high in psychopathy, in addition to their use of one-time sexual encounters, likely engage in enough mate retention to ensure fertilization is occurring in at least some of their affairs (de Miguel \& Buss, 2011). In sum, retaining a mate long enough for conception to take place is an additional hurdle that all reproductively successful individuals had to clear.

One solution to the dilemma of ensuring a partner's fidelity involves mate retention tactics (Buss, 1988). Buss (1988) suggests that mate retention tactics are the behavioral response to romantic jealousy in relationships. In fact, jealousy and fear of losing a partner are certainly explanations as to why some individuals use mate retention tactics. However, a second reason has to do with propriety (Shackelford \& Goetz, 2006). Individuals who feel a sense of entitlement or ownership over their partner are likely to feel justified in using mate retention tactics, and use them more often.

Shackelford and Goetz (2006) found that of the 19 mate retention tactics identified in the literature, 17 of them correlated positively and significantly with the Controlling Behavior Index (CBI; Dobash, Dobash, Cavangh, \& Lewis, 1998). The CBI measures a sense of propriety over a partner and is linked to psychological mistreatment and verbal violence. Romantic partners subjected to excessive mate retention tactics are likely to feel restricted freedom and they may feel in danger (Shackelford \& Goetz, 2006). Excessive mate retention tactics are also likely to 
drive a partner away in the long-run (Buss, 2000, p. 214). One empirical example comes from Sheets, Fredendall, and Claypool (1997) who found that jealousy evocation, a mate retention strategy, led to greater relationship conflict. Such conflict naturally leads to relationship dissolution for many couples. In sum, using excessive levels of mate retention tactics seems to present a trade-off: it deters infidelity but at the potential cost of relationship dissolution.

Short-term oriented individuals, however, may not have much to lose in the use of excessive mate retention tactics. In lieu of love or commitment, short-term strategists (such as individuals high in psychopathy) would have needed an alternative way to keep partners from getting pregnant from another rival, or devoting resources to another rival. Excessive mate retention tactics may have been the answer.

All three Dark Triad traits are defined by low levels of empathy (Wai \& Tiliopoulos, 2012). Thus, individuals high in any Dark Triad trait should be willing (in principle) to engage in negative retention tactics. Previous research has examined all three traits, and found mixed results with respect to the Dark Triad and mate retention tactics ${ }^{1}$ (Jonason, Li, \& Buss, 2010).

\section{Summary and Predictions}

Given the strategic nature of those high in Machiavellianism (Jones \& Paulhus, 2009), we predict that such individuals will not engage in negative mate retention tactics to the same degree when compared to the other two Dark Triad traits. This assertion stems from the fact that individuals high in Machiavellianism think in terms of long-term goals (Jones, 2016). Instead, we predict that the type of relationship an individual high in Machiavellianism is pursuing will dictate the degree to which aggressive mate retention tactics are used. Because of the flexibility

\footnotetext{
${ }^{1}$ Note that Jonason and colleagues examined the Dark Triad and mate retention but they forced the Dark Triad into a composite, which is statistically (Jones \& Figueredo, 2013) and theoretically (Glenn \& Sellbom, 2015) inappropriate. Further, Jonason, Li, and Buss (2010) reported disattenuated correlations that were smaller than the raw correlations, which indicates that there are statistical errors in the analyses.
} 
inherent in the construct of Machiavellianism, we predict that relationship type (short- vs. longterm) will alter willingness to engage in poor mate treatment (i.e., aggressive mate retention and infidelity). This assertion stems from the fact that mate retention tactics would serve short-term goals in short-term relationships. However, these same mating-related tactics would undermine long-term goals in long-term relationships. Given that narcissism and psychopathy are shortterm oriented traits (Jones \& Paulhus, 2011b), we predict that they will lack the requisite impulse control (psychopathy) or self-awareness (narcissism) necessary to alter their retention tactics regardless of relationship type.

\section{Study 1 - Cross-sectional Survey}

\section{Method}

\section{Participants}

A sample of 374 participants (63\% women; 79\% Caucasian, 6\% Black/AfricanAmerican, 5\% East Asian, 5\% Latino, 5\% mixed ethnicities) were recruited from Amazon's MTurk (Buhrmester, Kwang, \& Gosling, 2011; Paolacci, Chandler, \& Ipeirotis, 2010), for a study on "sexual behavior" for a standard MTurk fee $(\$ 0.25)$. The sample ranged in age from 18 to 66 (mean age $=30.71, \mathrm{SD}=10.06)$ and $72 \%$ reported currently being in a romantic relationship.

\section{Measures}

Psychopathy. We used the 64-item Self-Report Psychopathy (SRP) Scale (Paulhus, Neumann, \& Hare, 2016) to assess psychopathy, which was scored on a 1 (Strongly Disagree) to 5 (Strongly Agree) Likert-type scale. The SRP breaks into four inter-correlated facets of interpersonal manipulation, callous affect, erratic lifestyle, and antisocial behavior (e.g., "I would get a 'kick' out of scamming someone."). For the purposes of the present study, we examined the 
overall composite, which had high internal consistency $(\alpha=.92)$.

Machiavellianism. To assess Machiavellianism, we used the 20-item Mach-IV, which was scored on a 1 (Strongly Disagree) to 5 (Strongly Agree) Likert-type scale. The Mach-IV was designed to capture the amoral, cynical, and manipulative nature of the construct (e.g., "It is wise to flatter important people.”). The Mach-IV has a long history of use (Jones \& Paulhus, 2009), had high internal consistency as well $(\alpha=.83)$.

Narcissism. We used the 40-item Narcissistic Personality Inventory (NPI) to assess grandiose narcissism (Raskin \& Hall, 1979). The NPI assesses narcissism through a forced choice ( 1 = narcissistic, 0 = non-narcissistic) format (e.g., "I love to look at myself in the mirror."). The internal consistency was high for the NPI $(\alpha=.88)$.

Mate Retention Inventory: Short-Form (MRI-SF; Buss, Shackelford, \& McKibbin, 2008). The MRI-SF is a shortened version of the MRI (Buss, 1988). The MRI-SF was scored on a 1 (Never performed this act) to 4 (Often performed this act) Likert-type scale. The MRI-SF has a total of 38 items, the scale measures 19 different mate retention tactics ( 2 items per tactic). However, for the purposes of the present study, we isolated those MRI tactics that were negative, aggressive, or antisocial (e.g., "Became angry when my partner flirted too much"). Specifically, items 17, 18, 23, and 24 were considered positive or neutral and were removed (e.g., "Bought my partner an expensive gift"). In the present study, the total negative items from the MRI-SF showed high internal consistency $(\alpha=.89)$. Descriptive statistics for all measures can be found in Table 1. Because the two-item composites that make up the 19 tactics of the MRI-SF have poor internal consistencies (Jonason et al., 2010), we also examined correlations between the higher-order categories of the MRI-SF (i.e., Direct, Intersexual, Intrasexual, Public, \& Positive Induction) and the Dark Triad. However, we still included Dark Triad correlations along with 
the internal consistencies of the two item composites. Finally, we also asked several demographic questions such as how long participants had been in their relationship along with age, gender, and ethnicity.

\section{Results and Discussion}

As can be seen in Table 2, psychopathy has the highest association with each MRI-SF category. Table 3 also presents the correlations with the two-item composites. With respect to the overall composite of negative mate retention tactics, both psychopathy $(r=.18, p<.001)$ and narcissism, $(r=.15, p=.003)$ had significant correlations, and Machiavellianism had a smaller but marginally significant correlation $(r=.09, p=.077)$. Further, using a Fischer's z-test to determine correlation strength differences, the correlation between Machiavellianism and negative mate retention was significantly different from that of psychopathy and negative mate retention $(z=-2.23, p=.04)$. No other correlations significantly differed.

Given the significant difference in correlations between Machiavellianism and mate retention and psychopathy and mate retention, it is possible that Machiavellianism is merely spuriously related to mate retention through psychopathy. Thus, to test this possibility, we computed a partial correlation between Machiavellianism and mate retention, controlling for psychopathy. The results indicated that Machiavellianism $\left(r_{x y}=-.03, p=.514\right)$ had no relationship with negative mate retention when psychopathy was taken into consideration. However, it is important to note that the reverse was not true: even when controlling for Machiavellianism, psychopathy was still related to negative mate retention $\left(r_{x y}=.16, p=.002\right)$. All other partial correlations are reported in Table 4.

Next, negative mate retention tactics were regressed on the three Dark Triad traits. Note that we always standardized all Dark Triad traits prior to computing interactions. Further, we 
examined whether or not relationship length (i.e., greater or less than 1 year in a relationship), relationship status (in a current relationship or not), or self-reported biological sex had an impact on any of the associations, and they did not. The results indicated that psychopathy $(\beta=.17$, $95 \% C I=.03, .31, p=.019)$ was the only unique predictor of negative mate retention. $\operatorname{Narcissism}(\beta=.09,95 \% C I=-.02, .20, p=.113)$ and Machiavellianism $(\beta=-.04,95 \% C I=-$ $.17, .09, p=.537)$ were unrelated. With respect to positive mate retention tactics (Items17, 18 , 23, 24 on the MRI-SF) only Machiavellianism had a significant correlation, $r=-.11, p=.043$. We regressed positive mate retention on the three Dark Triad traits; however, none of them had significant associations.

Study 1 established that Machiavellianism differs from psychopathy with respect to the use of negative mate retention tactics. In particular, Machiavellian individuals have no unique association with the use of such tactics. Given the callousness and manipulation associated with the trait (Jones \& Figueredo, 2013), it is likely that they have strategic reasons (not ethical ones) for curtailing the use of such tactics. Thus, it is likely that their willingness to engage in such tactics is moderated by the type of relationship which they might be pursuing.

\section{Study 2 - Experiment}

Context may matter when it comes to aggressive use of negative mate retention tactics among individuals high in Machiavellianism. The null findings here with respect to Machiavellianism may indicate that such individuals are no more or less likely to use these tactics than is anyone else. However, it could also indicate that relationship type may matter to an individual high in Machiavellianism in deciding whether or not to use such negative mate retention tactics. To explore these possibilities, we compared conditions where individuals high in Machiavellianism should engage in high levels of negative mate retention. Given that it is 
strategically advantageous to use negative mate retention tactics in short-term relationships (because they pose no cost), we predicted that individuals high in Machiavellianism would use high levels of negative mate retention tactics in short-term situations. Conversely, individuals high in Machiavellianism should show average levels of negative mate retention in long-term situations. This prediction stems from the fact that there is no cost to using excessive mate retention tactics in a short-term relationship given that relationship dissolution is not a concern.

Lastly, as Shackelford and Goetz (2006) have pointed out, it is often unclear what someone's motivation is for endorsing some mate retention items because sometimes these behaviors lead to violence, and sometimes not (Shackelford et al., 2005). To address this potential limitation, we included instructions in the experimental manipulation that asked participants to suspect infidelity in a hypothetical scenario in a long or short-term situation. In this way we are able to be assured that responses addressed potential infidelity, in the true spirit of mate retention literature (Buss, 1988).

We predicted that the amount of mate retention tactics used by individuals high in psychopathy and narcissism would not differ across short and long-term relationships. Their over-riding impulsivity and fragility (respectively) would lead to less discrimination across situations. Individuals high in Machiavellianism, however, are predicted to temper their negative mate retention tactics for long-term relationships, because such behavior would undermine their long-term goal of mate retention. However, when it is useful and bears no cost (i.e., short-term relationships), individuals high in Machiavellianism are predicted to engage in high levels of negative mate retention tactics. In sum, we predict individuals high in Machiavellianism will engage in high levels of negative mate retention for short-term, but not long-term, relationships.

\section{Methods}




\section{Participants}

An MTurk sample, consisting of 190 individuals, was recruited (90 men; 100 women; 57\% Caucasian, 25\% East Asian, 18\% other ethnicities) for a study on "sexual behavior." The sample ranged in age from 18 to 66 (mean age $=29.88, \mathrm{SD}=9.84$ ) and $70 \%$ reported currently being in a romantic relationship.

\section{Design and procedure}

Participants who agreed to participate accessed a website containing the questions. All participants first filled out demographic questionnaires and measures of the Dark Triad (same as Study 1). Participants were then randomly assigned to think about a long-term relationship or a short-term relationship. All participants were told to imagine that they suspected that their partner might be unfaithful in the future. Participants were asked to rate how likely they would be to engage in the following behaviors, and were then given a modified version of the Mate Retention Inventory (Short-form). The modification simply framed the questions in present or future tense rather than past tense (e.g., "Snooped through my partner's personal belongings," was changed to "Snoop through my partner's personal belongings." "Did not take my partner to a party where other women would be present," was changed to, "Not take my partner to a party where other women would be present."). As a result, every question logically followed from the question "how likely would you be to engage in the following behaviors?" Each item was measured on a Likert-type scale of 1 (not at all likely) to 5 (extremely likely).

\section{Measures}

Dark Triad. We used the same scales and response options as Study 1 to measure the Dark Triad. All three had high internal consistency (MACH-IV $\alpha=.78$; NPI $\alpha=.89$; SRP $\alpha$ $=.93)$. The SRP was again positively correlated with the Mach-IV $(r=.57, p<.001)$ and the 
NPI $(r=.50, p=.001)$. Further the Mach-IV correlated with the NPI $(r=.26, p<.001)$.

Mate Retention Inventory Short-Form (MRI-SF; Buss, Shackelford, \& McKibbin, 2008). The MRI-SF was adapted, as aforementioned, for the present study by asking participants how likely ( 1 = Not at all Likely, $5=$ Extremely Likely) they would be to engage in each behavior, rather than how often. As in Study 1, we focused primarily on negative MRI-SF items.

\section{Results and discussion}

We regressed the negative mate retention items onto the Dark Triad and condition (shortvs. long-term) in Step 1, and the three interactions of condition*Machiavellianism, condition*narcissism, and condition*psychopathy in Step 2. Table 5 shows that psychopathy was again the only predictor of mate retention in Step 1. However, Step 2 reveals a significant Machiavellianism*condition interaction. Figure 1 displays this interaction; note that all figures are graphed using one standard deviation above and below the mean of Machiavellianism. Specifically, Figure 1 illustrates that individuals high in Machiavellianism who were asked to think of a short-term relationship were most aggressive in their use of negative mate retention tactics. However, these tactics were not endorsed among individuals high in Machiavellianism thinking about long-term relationships. No other interactions emerged. Once again, it should be noted that neither self-reported gender nor relationship status moderated the results. However, given the high inter-correlations typically observed among the Dark Triad variables, it was necessary to examine each Dark Triad*condition interaction in isolation. Specifically, Psychopathy $(\beta=.29 ; 95 \% C I=.15, .43 ; p<.001)$ and $\operatorname{narcissism}(\beta=.24 ; 95 \% C I=.09, .38 ; p=$ .001) only had significant main effects. Although Machiavellianism had a significant main effect as well $(\beta=.20 ; 95 \% C I=.05, .34 ; p=.008)$, there was also a significant interaction with condition $(\beta=-.72 ; 95 \% C I=-1.18,-0.25 ; p=.003)$. Thus, the results did not change regardless 
of looking at the Dark Triad one at a time, or together. In sum, these findings highlight the flexibility of Machiavellian individuals when it comes to mate retention. In particular, Machiavellian individuals are zealous in aggressive mate retention -- but only when it is beneficial to do so.

We also examined a regression predicting positive mate retention tactics. The results indicated that no significant main effects or interactions emerged. It is important to note that the interaction between relationship type and Machiavellianism was marginal and in the same direction as the negative tactics $(\beta=-.57 ; 95 \% C I=-1.16,0.03 ; p=.060)$. One explanation for this finding is that participants were instructed to think about the possibility of infidelity regardless of condition. In the case of suspected infidelity, individuals high in Machiavellianism may simply be non-reactionary, which would underscore their strategic nature (Jones, 2016). We will return to this point in the General Discussion.

Study 2 established that negative mate retention tactics are most likely to be used by individuals high in Machiavellianism for short-term relationships. Further, among the Dark Triad, these tactics are least used by individuals high in Machiavellianism in long-term relationships. Although these findings are encouraging, it is necessary to replicate this shortterm vs. long-term effect in a different sample and using a different negative behavior: infidelity.

\section{General Discussion}

The Dark Triad traits are overlapping but distinct. Although there is a common callousmanipulative core uniting the Dark Triad, each trait has residual components making it unique (Jones \& Figueredo, 2013). In particular, individuals high in Machiavellianism are unique through their cynical worldview and their strategic form of manipulation. More specifically, such individuals are behaviorally and cognitively flexible (Bereczkei, 2015). As a consequence 
they calibrate their behavior and manipulation to a given situation to maximize their long-term goals (Jones, 2016). In terms of behavior when in a relationship, their use of reckless or negative tactics depends on the nature of the relationship itself and how such behaviors may affect longterm goals. Whereas individuals high in psychopathy and narcissism are impulsive and reactive (respectively), and lack the ability to engage in relationship accommodation processes, individuals high in Machiavellianism do have the requisite self-control necessary to inhibit destructive impulses in the service of long-term goals (Jones \& Paulhus, 2016). In sum, we predicted that there would be no association in current relationships with respect to Machiavellianism and the use of negative mate retention tactics. We further predicted that Machiavellian use of such tactics would depend entirely on the type of relationship being pursued; these predictions were supported.

Study 1 found that individuals high in Machiavellianism were neutral when it came to the use of negative mate retention tactics. In Study 2, individuals high in Machiavellianism were unwilling to engage in behaviors that undermined their long-term goals for short-term benefits. Specifically individuals high in Machiavellianism did not report intentions to engage in negative mate retention tactics for long-term relationships. However, individuals high in Machiavellianism reported a high willingness to engage in these tactics for short-term relationships. Thus, with respect to romantic relationships, individuals high in Machiavellianism report engaging in accommodation processes (Rusbult, Verette, Whitney, Slovik, \& Lipkus, 1991), when they are asked to imagine a long-term relationship.

The finding that individuals low in Machiavellianism are not engaging in negative mate retention tactics may be surprising given that such tactics are assumed to be useful in deterring (at least in the short-term) infidelity on the part of a partner (Buss, 1988). Note that these tactics 
are aggressive and antisocial (Shackelford \& Goetz, 2006), and it would require a certain level of callousness in order to engage in them (Jones \& Paulhus, 2013). Further, it is worth noting that individuals low in Machiavellianism did (marginally) increase positive mate retention tactics in long-term relationships. Thus, a "softer touch" may be what individuals low in all three Dark Triad traits strive for when attempting to retain a partner.

It may be surprising, however, that strategically manipulative individuals, such as those high in Machiavellianism would not use positive mate retention tactics in Study 2. Note, however, that in Study 2, participants were asked to imagine suspected infidelity. From a strategic perspective, engaging in costly signaling (e.g., buying expensive gifts) or other positive mate retention displays may also be counterproductive. It may simply be that individuals high in Machiavellianism are non-reactive when a potential long-term goal might be compromised by immediate action. Future research should examine how much time an individual high in Machiavellianism takes to make a decision in breaking up with a long- vs. short-term partner after suspected infidelity. Further, it may be the case that such individuals gather as much information as possible prior to acting, unlike individuals high in other Dark Triad traits.

With respect to other Dark Triad traits, we found that psychopathy was the best predictor of negative mate retention tactics in current relationships. Further, narcissism had a small but positive association with public and positive induction mate retention tactics, whereas Machiavellianism was negatively associated with public tactics. To speculate on this finding, it may be possible that this finding is driven by the private and secretive nature of the Machiavellian character. Further, such tactics may be either costly or may lead to unwanted attachment that individuals high in Machiavellianism seek to avoid. On the other hand, because of their overconfidence and charming nature, narcissistic individuals may find these retention 
strategies come more naturally, and the future consequences are ignored. However, these speculative explanations require future research.

In the Study 2 experiment, individuals high in Machiavellianism demonstrated flexibility in their treatment of a partner. In fact, individuals high in Machiavellianism were most aggressive when thinking of a short-term relationship. However, in the context of long-term relationships, only individuals high in Machiavellianism backed away from aggressive mate retention tactics. We argued that aggressive mate retention occurs as a solution to discouraging infidelity in one's partner long enough to allow fertilization to occur (de Miguel \& Buss, 2011). Thus, it is entirely possible that men high in Machiavellianism engage in aggressive retention tactics only at certain times of the month, specifically, when his partner is fertile. Further, in considering short-term relationships, it is possible that aggressive mate retention tactics are used only until fertilization occurs or to stave off a rival. Future research should track relationships in a longitudinal fashion to determine if aggressive use of mate retention tactics in men high in Machiavellianism coincides with his partner's menstrual cycle.

Future research should also examine the Dark Triad traits and retaliatory behaviors in the context of long- vs. short-term relationships. For example, if a romantic partner is highly valuable (e.g., rich, high social status) but is unfaithful, will the Machiavellian partner who is betrayed retaliate? Fitness (2001) argued that individuals may react destructively and in a retaliatory fashion to betrayal, especially when a partner's transgression was severe and the partner is relatively unremorseful. However, Fitness also notes that if a betrayed partner perceives that they need their romantic partner, forgiveness may take place. In the case of Machiavellianism, individuals may never forgive or forget the transgression, but may curtail the use of destructive tactics because of bigger goals they may have for the future. 
There are several limitations to the present study. First, the data were all self-reported and cross-sectional. Second, we did not define for participants what we meant by "short-term" and "long-term" relationships. It is possible that different participants interpreted these terms differently. It should also be noted that our short- vs. long-term relationship manipulation may be especially ambiguous with respect to infidelity. Some may argue whether infidelity can occur within a short-term relationship. Indeed, individuals may regard such relationships with more flexible boundaries surrounding sexual encounters with others. Individuals in short-term relationships may still care about the fidelity of their partner, only insofar as it ensures short-term resource allocation or paternity certainty (see Buss, 2003, for review). In particular, much like mate retention tactics, individuals may expect fidelity even in short-term relationships, although there are no long-term aspirations for the relationship (Buss, 2000). One final limitation was that the experimental manipulation relied on hypothetical scenarios. Future research could address some of these limitations by examining relationship conversations and behaviors in the laboratory among couples who are in self-reported short- vs. long-term relationships.

Nevertheless, our primary interest was in whether individuals high in Machiavellianism were potentially more cautious in long-term relationships with respect to relationship-harming behaviors. The overall results indicated that individuals high in Machiavellianism do indeed temper their aggressive mate retention tactics in long-term relationships. It should also be noted that these findings replicate previous research on the Dark Triad and infidelity (Jones \& Weiser, 2014). Jones and Weiser found that women high in Machiavellianism were just as likely as women high in psychopathy to have been unfaithful in a current relationship. However, across all infidelity, Machiavellianism was negatively associated with relationship dissolution.

In general, these findings are in line with previous research and theory linking 
Machiavellianism to flexible behavioral tactics (Bereczkei, 2015). However, this research extends those findings to the realm of personal relationships. Although only psychopathy was uniquely related to retrospective reports of negative use of negative mate retention tactics, all three Dark Triad traits, under the right circumstances, may engage in negative mate retention behaviors. However, only the individuals high in Machiavellianism appeared to consider the consequences of such tactics and how they might affect long-term relationship goals.

\section{Summary and conclusions}

Given that the Dark Triad traits are similar in many areas, one might assume that individuals high in different Dark Triad traits behave similarly in the realm of mating strategies (e.g., Jonason et al., 2012). However, one must look beyond the correlational results and control for the overlap between the three traits of the Dark Triad in order to examine when the differences among them would be relevant. This approach should be guided by theory as to whether circumstances dictate long- vs. short-term strategy (e.g., Jones, 2014). Although there may be some circumstances where being callous is the only link the Dark Triad may have to a particular outcome, when behavioral flexibility is required, Machiavellianism is likely to be the best predictor.

The results of the two studies provide evidence for the argument that the Dark Triad are distinct but overlapping in the realm of mate treatment and that the Dark Triad traits are associated with varied mating strategies. Their similarity in callous-manipulation might be the product of a process similar to "convergent evolution," where different traits converge to exhibit similar patterns of behavior. Therefore, even the similarities in the Dark Triad may have unique etiologies. 


\section{References}

Back, M. D., Schmukle, S. C., \& Egloff, B. (2010). Why are narcissists so charming at first sight? Decoding the narcissism-popularity link at zero acquaintance. Journal of personality and social psychology, 98, 132.

Bagozzi, R. P., Verbeke, W. J., Dietvorst, R. C., Belschak, F. D., van den Berg, W. E., Wouter, E.B., \& Rietdijk, W. J. (2013). Theory of mind and empathic explanations of Machiavellianism: A neuroscience perspective. Journal of Management, 39, 1760-1798.

Bereczkei, T. (2015). The manipulative skill: Cognitive devices and their neural correlates underlying Machiavellian's decision making. Brain and cognition, 99, 24-31.

Blair, R.J.R. (2001). Advances in neuropsychiatry: Neurocognitive models of aggression, the antisocial personality disorders, and psychopathy. Journal of Neurology, Neurosurgery, and Psychiatry, 71, 727-731.

Buhrmester, M., Kwang, T., \& Gosling, S. D. (2011). Amazon's Mechanical Turk a new source of inexpensive, yet high-quality, data?.Perspectives on psychological science, 6, 3-5.

Buss, D. M. (1988). From vigilance to violence: tactics of mate retention. Ethology and Sociobiology, 9, 291-317.

Buss, D. M. (2000). The dangerous passion. New York: Free Press.

Buss, D. M. (2003). The evolution of desire: Strategies of human mating. Basic books.

Buss, D.M., Shackelford, T.K., McKibbin, W.F. (2008). The Mate Retention Inventory-Short Form (MRI-SF). Personality and Individual Differences, 44, 322-334.

Campbell, W., Goodie, A. S., \& Foster, J. D. (2004). Narcissism, confidence, and risk attitude. Journal of Behavioral Decision Making, 17, 297-311.

Christie, R., \& Geis, F. L. (1970). Studies in Machiavellianism. New York: Academic Press. Cleckley, H. (1976). The mask of sanity (4th Ed). St. Louis: Mosby. 
Czibor, A., \& Bereczkei, T. (2012). Machiavellian people's success results from monitoring their partners. Personality and Individual Differences, 53, 202-206.

de Miguel, A., \& Buss, D.M. (2011). Mate Retention Tactics in Spain: Personality, Sex Differences, and Relationship Status. Journal of Personality, 79, 563-585.

Dobash, R. E., Dobash, R. P., Cavanagh, K., \& Lewis, R. (1998). Separate and intersecting realities: a comparison of men's and women's accounts of violence against women. Violence Against Women, 4, 382-414.

Esperger, Z., \& Bereczkei, T. (2012). Machiavellianism and spontaneous mentalization: one step ahead of others. European Journal of personality, 26, 580-587.

Eysenck, H. J. Sex and personality. Austin: University of Texas Press, 1976.

Figueredo, A.J., Vasquez, G., Brumbach, B.H., \& Schneider, S.M.R. (2007). The K-Factor, covitality, and personality: A psychometric test of Life History Theory. Human Nature, $18,47-73$

Figueredo, A.J., Vasquez, G., Brunbach, B.H., Schneider, S.M.R., Sefcek, J.A., Tal, I.R., Hill, D., Wenner, C.J., \& Jacobs, W.J. (2006). Consilience and Life History Theory: From genes to brain to reproductive strategy. Developmental Review, 26, 243-275.

Figueredo, A.J., Vasquez, G., Brumbach, B.H., Sefcek, J.A., Kirsner, B.R., \& Jacobs, W.J. (2005). The K-factor: Individual differences in life history strategy. Personality and Individual Differences, 39, 1349-1360.

Gangestad, S.W., \& Simpson, J. A. (2000). The evolution of human mating: Trade-offs and strategic pluralism. Behavioral and Brain Sciences, 23, 573-587.

Gentile, B., Miller, J. D., Hoffman, B. J., Reidy, D. E., Zeichner, A., \& Campbell, W. K. (2013). A test of two brief measures of grandiose narcissism: The Narcissistic Personality 
Inventory-13 and the Narcissistic Personality Inventory-16. Psychological assessment, 25, 1120-1136.

Gladden, P. R., Figueredo, A. J., \& Jacobs, W. J. (2009). Life history strategy, psychopathic attitudes, personality, and general intelligence. Personality and Individual Differences, $46,270-275$.

Glenn, A. L., \& Sellbom, M. (2015). Theoretical and empirical concerns regarding the dark triad as a construct. Journal of personality disorders, 29, 360-377.

Harms, P. D., Williams, K. M., \& Paulhus, D. L. (2001). Predictors of love-proneness vs. lustproneness. Poster presented at the 109th annual convention of the American Psychological Association, San Francisco.

Hawley, P.H. (2003). Prosocial and coercive configurations of resource control in early adolescence: A case for the well-adapted Machiavellian. Merrill-Palmer Quarterly, 49, 279-309.

Hawley, P.H., Little, T.D., \& Card, N.A. (2007). The allure of a mean friend: Relationship quality and processes of aggressive adolescents. International Journal of Behavioral Development, 31, 170-180.

Jonason, P. K., Koenig, B. L., \& Tost, J. (2010). Living a fast life. Human Nature, 21, 428-442.

Jonason, P. K., Li, N. P., \& Buss, D. M. (2010). The costs and benefits of the Dark Triad: Implications for mate poaching and mate retention tactics. Personality and Individual Differences, 48, 373-378.

Jonason, P.K., Li, N.P., Webster, G.D., Schmitt, D.P. (2009). The Dark Triad: Facilitating a short-term mating strategy in men. European Journal of Personality, 23, 5-18.

Jonason, P. K., \& Tost, J. (2010). I just cannot control myself: The Dark Triad and self- 
control. Personality and Individual Differences, 49, 611-615.

Jones, D.N. (2014). Predatory personalities as behavioral mimics and parasites: MimicryDeception Theory. Perspectives on Psychological Science, 9, 445-451.

Jones, D.N. (2016). The nature of Machiavellianism: Distinct patterns of misbehavior. In V. Zeigler-Hill \& D.K. Marcus (Eds.), The dark side of personality: Science and practice in social, personality, and clinical psychology (pp. 87-107). Washington DC: American Psychological Association.

Jones, D.N., \& de Roos, M. (2016). Differential reproductive patterns among the Dark Triad. Manuscript Under Review.

Jones, D.N., \& Figueredo, A.J. (2013). The core of darkness: uncovering the heart of the Dark Triad. European Journal of Personality, 27, 521-531.

Jones, D.N., \& Paulhus, D.L. (2010). Different provocations provoke aggression in psychopaths and narcissists. Social Psychological and Personality Science, 1, 12-18.

Jones, D. N., \& Paulhus, D. L. (2011a). Differentiating the dark triad within the interpersonal circumplex. In L. M. Horowitz \& S. N. Strack (Eds.), Handbook of interpersonal theory and research (pp. 249-267). New York, NY: Guilford.

Jones, D.N., \& Paulhus, D.L. (2009). Machiavellianism. In M.R. Leary \& R.H. Hoyle (Eds.), Handbook of individual differences in social behavior (pp. 93-108). New York: Guilford.

Jones, D.N., \& Paulhus, D.L. (2011b). The role of impulsivity in the Dark Triad of personality. Personality and Individual Differences, 51, 670-682.

Jones, D. N., \& Weiser, D. A. (2014). Differential infidelity patterns among the Dark Triad. Personality and Individual Differences, 57, 20-24.

Jones, D.N., \& Paulhus, D.L. (2016). Shades of duplicity among the Dark Triad: Three faces of 
deceit. Manuscript Under Review.

Kashy, D. A., \& DePaulo, B. M. (1996). Who lies? Journal of Personality and Social Psychology, 70, 1037-1051.

Kernberg, O. (1975). Borderline Conditions and Pathological Narcissism. New York: Jason Aronson.

Kenrick, D.T., \& Trost, M.R. (1989). A reproductive exchange model of heterosexual relationships: Putting proximate economics in ultimate perspective. In C. Hendrick (Ed.), Review of Personality and Social Psychology (Vol.10, pp. 92-118). Newbury Park, CA: Sage.

Kohut, H. (1971). The Analysis of the Self. New York: International Universities Press.

LeBreton, J. M., Binning, J. F., \& Adorno, A. J. (2005). Subclinical psychopaths. In J. C. Thomas \& D. Segal (Eds.), Comprehensive handbook of personality and psychopathology: Vol. 1. Personality and everyday functioning (pp. 388-411). New York: Wiley.

Linton, D.K., \& Wiener, N.I. (2001). Personality and potential conceptions: mating success in a modern western male sample. Personality and Individual Differences, 31, 675-688.

McDonald, M. M., Donnellan, M. B., \& Navarrete, C. D. (2012). A life history approach to understanding the Dark Triad. Personality and Individual Differences, 52, 601-605.

McHoskey, J.W. (2001). Machiavellianism and sexuality: on the moderating role of biological sex. Personality and Individual Differences, 31, 779-789.

Mealey, L. (1995). The sociobiology of sociopathy: An integrated evolutionary model. Behavioral and Brain Sciences, 18, 523-599.

Neumann, C. S., \& Pardini, D. (2014). Factor structure and construct validity of the Self-Report 
Psychopathy (SRP) Scale and the Youth Psychopathic Traits Inventory (YPI) in young men. Journal of Personality Disorders, 28, 419-433.

Newman, J. P. (1987). Reaction to punishment in extraverts and psychopaths: Implications for the impulsive behavior of disinhibited individuals. Journal of Research in Personality, 21, 464-480.

Newman, J. P., \& Kosson, D. S. (1986). Passive avoidance learning in psychopathic and nonpsychopathic offenders. Journal of Abnormal Psychology, 95, 252.

O'Boyle Jr, E. H., Forsyth, D. R., Banks, G. C., \& McDaniel, M. A. (2012). A meta-analysis of the dark triad and work behavior: A social exchange perspective. Journal of Applied Psychology, 97, 557579.

Paolacci, G., Chandler, J., \& Ipeirotis, P. G. (2010). Running experiments on Amazon's Mechanical Turk. Judgment and Decision making, 5, 411-419.

Paulhus, D. L. (1998). Interpersonal and intrapsychic adaptiveness of trait self-enhancement: A mixed blessing? Journal of Personality and Social Psychology, 74, 1197-1208.

Paulhus, D. L., Neumann, C. S., \& Hare, R. D. (2016). Manual for the Self-Report Psychopathy scale (4th ed). Toronto: Multi-Health Systems.

Paulhus, D. L., \& Williams, K. M. (2002). The Dark Triad of personality: Narcissism, Machiavellianism, and psychopathy. Journal of Research in Personality, 36, 556-563.

Raskin, R., \& Hall, C. S. (1979). A Narcissistic Personality Inventory. Psychological Reports, $45,590$.

Reise, S.P., \& Wright, T.M. (1996). Personality traits, cluster B personality disorders, and sociosexuality. Journal of Research in Personality, 30, 128-136.

Rowe, D. C., Vazsonyi, A. T., \& Figueredo, A. J. (1997). Mating effort in adolescence. Conditional or alternative strategy? Personality and Individual Differences, 23, 105-115. Rusbult, C. E., Bissonnette, V. L., Arriaga, X. B., Cox, C. L., \& Bradbury, T. N. (1998). 
Accommodation processes during the early years of marriage. The developmental course of marital dysfunction, 74-113.

Rusbult, C. E., Verette, J., Whitney, G. A., Slovik, L. F., \& Lipkus, I. (1991). Accommodation processes in close relationships: Theory and preliminary empirical evidence. Journal of Personality and Social Psychology, 60, 53-78.

Seto, M.C., Khattar, N.A., Lalumiere, M.L., \& Quinsey, V.L. (1997). Deception and sexual strategy in psychopathy. Personality and Individual Differences, 22, 301-307.

Shackelford, T.K. \& Goetz, A.T. (2006). Predicting violence against women from men's materetention behaviors. In S.M. Platek and T.K. Shackelford (Eds.), Female infidelity and paternal uncertainty, (pp. 58-81) Cambridge, UK: Cambridge University Press.

Shackelford, T.K., Goetz, A.T., Buss, D.M., Euler, H.A., \& Hoier, S. (2005). When we hurt the ones we love: Predicting violence against women from men's mate retention. Personal Relationships, 12, 447-463.

Sheets, V.L., Fredendall, L.L., Claypool, H.M. (1997). Jealousy evocation, partner reassurance, and relationship stability: An exploration of the potential benefits of jealousy. Evolution and Human Behavior, 18, 387-402.

Spitzer, M., Fischbacher, U., Herrnberger, B., Gron, G., \& Fehr, E. (2007). The neural signature of social norm compliance. Neuron, 56, 185-196.

Thornhill, R., \& Alcock, J. (1983). The evolution of insect mating systems. Cambridge, MA: Harvard University Press.

Tooke, W. \& Camire, L. (1991). Patterns of deception in intersexual and intrasexual mating strategies. Ethology and Sociobiology, 12, 345-364.

Vazire, S., \& Funder, D. C. (2006). Impulsivity and the self-defeating behavior of narcissists. Personality and Social Psychology Review, 10, 154-165. 
Verbeke, W. J., Bagozzi, R. P., Rietdijk, W. J., van den Berg, W. E., Dietvorst, R. C., \& Worm, L. (2011). The making of the Machiavellian brain: A structural MRI analysis. Journal of Neuroscience, Psychology, and Economics, 4, 205-216.

Vernon, P.A., Villani, V.C., Vickers, L.C., \& Harris, J.A. (2008). A behavioral genetic investigation of the Dark Triad and the Big 5. Personality and Individual Differences, 44, 445-452.

Wai, M., \& Tiliopoulos, N. (2012). The affective and cognitive empathic nature of the dark triad of personality. Personality and Individual Differences, 52, 794-799. 
Machiavellian Mating - 30

Figure 1. Machiavellianism $\times$ Relationship Type in Predicting Negative Mate Retention Tactics. 